EGU21-16332

EGU General Assembly 2021

(c) Author(s) 2021. This work is distributed under

the Creative Commons Attribution 4.0 License.

\title{
Geophysical signature of the alpine slab: Field analogues and direct models
}

Manon Sonnet ${ }^{1}$, Loïc Labrousse ${ }^{1}$, Jérôme Bascou ${ }^{2}$, and Alexis Plunder ${ }^{3}$

${ }^{1}$ Institut des Sciences de la Terre de Paris, Sorbonne Université, Paris, France

${ }^{2}$ Laboratoire de Géologie de Lyon, Université de Saint Etienne, Saint-Etienne, France

${ }^{3}$ BRGM, Orléans, France

Recent geophysical data (receiver functions and body wave tomography) in the Alps show the continuity of the alpine dipping slab with the lower continental crust of the European plate. The eclogitization of the continental crust is often mentioned to explain its signature and its disappearing in the mantle beneath $80 \mathrm{~km}$.

The aim of the present study is to use potential lithological analogues sampled in the outcropping European crust to directly predict the seismic properties of the buried crust. Here, we focus on mafic intercalations, present in the variscan basement series of the external crystalline massifs. We compare them with acknowledged generic chemical compositions for the continental lower crust or regional granulite facies rock units. Using the bulk rock chemistries of these samples and representative rocks, we calculate pressure-temperature on which we represent the seismic velocities ( $\mathrm{Vp}$, Vs ot $\mathrm{Vp} / \mathrm{Vs}$ ) assuming that the rocks have completely rebalanced during burial. In these diagrams, the main seismic contrasts seem to match the onset of jadeite formation (mostly $\mathrm{Vp} / \mathrm{Vs}$ diagram), as well as the boundaries of the garnet and omphacite stability fields.

Considering the selected rocks are relevant analogues, we then compare the evolution of the seismic properties along the top of the alpine dipping slab with the profiles deduced from recent $V p$ and Vs tomography models (CIFALPS and AlpArray), varying the effective thermal profile of the Alpine slab, its reaction rate and its overall chemistry. Preliminary results suggest the Alpine lower crustal slab inherited most of his properties from its burial stage, with limited impact of subsequent evolution. 